\title{
Perbandingan Efisiensi Energi Pengontrol T2FSMC dan Pid pada Prototype Panel Surya
}

\author{
Gresela Sitorus, Mardlijah, dan Noorman Rinanto \\ Departemen Matematika, Fakultas Matematika Komputer dan Sains Data, Institut Teknologi Sepuluh \\ Nopember (ITS) \\ e-mail: sitorusgresela@gmail.com
}

\begin{abstract}
Abstrak-Panel surya akan menghasilkan nergi maksimal jika posisi panel surya tegak lurus dengan arah sinar matahari. Untuk itu diperlukan pengendali posisi panel surya. Dalam penelitian ini, pengendali yang digunakan adalah T2FS MC dan PID dan selanjutnya dilakukan perbandingan nilai efisiensi energi dari data penelitian yang dihasilkan oleh pengendali T2FSMC terhadap PID. Pada penelitian ini diperoleh nilai energi yang dihasilkan pengendali T2FSMC yaitu 12,99 Wh pada percobaan pertama dan 16,07 Wh pada percobaan kedua sedangkan untuk pengendali PID diperoleh nilai energi yaitu sebesar 1,39 Wh pada percobaan pertama dan 5,24 Wh pada percobaan kedua. Persentasi efisiensi energi pengendali T2FSMC terhadap PID yang diperoleh yaitu sebesar $89,30 \%$ pada percobaan pertama atau setara dengan 11,60 Wh energi yang dihasilkan setiap 5 menitnya dan pada percobaan kedua diperoleh sebesar 67,39\% atau setara dengan 10,83 Wh energi yang dihasilkan setiap 5 menitnya. Dari penelitian ini dapat disimpulkan bahwa kendali T2FSMC baik digunakan sebagai pengendali pada prototype panel surya karena menghasilkan nilai energi yang optimal.
\end{abstract}

Kata Kunci-Panel Surya, Sistem Pengendali, Type 2 Fuzzy Sliding Mode Control (T2FSMC), Proportional Integral Derivative (PID), Efisiensi Panel Surya.

\section{PENDAHULUAN}

M ATAHARI merupakan salah satu sumber energi yang dapat diperbaharui dan mendapat mendapat banyak perhatian untuk menggantikan bahan bakar fosil yang semakin menipis dan polusi udara yang ditimbulkan. Pemanfaatan matahari sebagai sumber energi yang dapat diperbaharui yakni konversi radiasi matahari menjadi energi listrik dengan menggunakan sel surya atau photovoltaic. Sel surya dikenal sebagai teknologi yang bersih, ramah lingkungan, serta memiliki biaya perawatan yang rendah. Namun, penggunaan sistem photovoltaic ini masih menjadi kendala untuk digunakan secara meluas di masyarakat dikarenakan biaya investasi yang mahal. Hal tersebut berbanding terbalik dengan nilai efisiensi yang rendah. Nilai efisiensi dari sebuah sistem PV bergantung pada beberapa faktor yakni radiasi solar, temperatur, posisi panel dan kondisi dari panel PV itu sendiri (misalnya : usia panel, kebersihan panel, dan lainnya) [1][2]. Dari beberapa faktor tersebut, diperlukan desain terhadap sistem PV untuk menghasilkan efisiensi dan daya paling optimum dalam berbagai kondisi lingkungan agar penggunaannya dapat semakin luas.

Banyak pengembangan yang telah dilakukan tentang pengendali pada panel surya. Tahun 2017 telah dilakukan identifikasi parameter sistem penggerak pada prototype panel surya sehingga model matematika yang teridentifikasi mereprentasikan kondisi prototype panel surya sebenarnya [3], penelitian selanjutnya pada tahun 2017 dikembangkan perancangan kendali T2SFMC dan kendali PID yang digunakan untuk mengendalikan kecepatan sudut pada panel surya, dari penelitian tersebut diperoleh bahwa kinerja kendali T2SFMC memiliki kinerja lebih baik dibandingkan kendali PID, namun pada penelitian ini tidak mempertimbangkan faktor cuaca [4]. PID (Proportional Integral Derivative) banyak digunakan dalam berbagai penelitian. Hal ini dikarenakan keberhasilan pengendali PID yang bergantung pada ketepatan dalam menentukan konstanta. Pengendali PID memiliki kelemahan yakni konstanta pada pengendali ini selalu sama untuk setiap nilai error yang terjadi dan diperlukan penalaan ulang jika terjadi perubahan parameter plant pada konstanta PID [4].

\section{METODE PENELITIAN}

Pada bagian ini dijelaskan mengenai teori yang digunakan dalam penelitian untuk mendapatkan nilai efisiensi energi dan pengontrol yang paling baik.

\section{A. Model Matematika PV}

Sel surya atau sel PV dapat megubah secara langsung energi radiasi matahari menjadi energi lis trik. Karakteristik arus dan tegangan yang dihasilkan panel PV secara matematis ditulis sebagai berikut [5] :

$$
I=I_{p h}-I_{s}\left[\exp \left\{\frac{q\left(V_{p w}+I_{p v} R_{S}\right]}{n K T}\right\}-1\right]-\frac{V_{p w}+I_{p v} R_{S}}{R_{m h}}
$$

Dengan :

$$
\begin{aligned}
& I_{0}=\text { arus saturasi reverse (ampere) } \\
& V=\text { tegangan antara terminal keluaran (volt) } \\
& R_{S}=\text { resistansi seri }(\text { ohm) } \\
& n=\text { fakor ideal dioda (kis aran } 1-7,5) \\
& K=\text { konstanta Boltzmann }\left(1,38 \times 10^{-19} J / K\right) \\
& T=\text { temperatur absolut } \\
& R_{S H}=\text { resistansi shunt (ohm) } \\
& N_{P}=\text { jumlah sel surya yang dihubungkan paralel }
\end{aligned}
$$




$$
N_{S}=\text { jumlah sel surya yang dihubungkan }
$$

\section{B. Efisiensi Panel Surya}

Pada sub bagian ini, akan dibahas efisiensi panel surya dalam mengkonversi energi cahaya yang diterima. Umumnya suatu panel surya dapat mengkonversi sekitar $20 \%$ energi cahaya. Efisiensi panel surya secara matematis ditulis sebagai berikut :

$\eta=\frac{P_{m}}{E \times A c}$

Dengan :

$\mathrm{Pm}=$ Output daya sel pada maksimum powerpoint (Watt)

$\mathrm{E}=$ cahaya masukan $\left(\mathrm{W} / \mathrm{m}^{2}\right)$

Ac $=$ luas permukaan sel surya $\left(\mathrm{m}^{2}\right)$

Namun pada penelitian ini difokuskan pada perbandingan kinerja dari dua pengendali yaitu T2FSMC dan PID yang dipasang pada prototype panel surya. Dimana hasil dari T2FSMC dibandingkan dengan hasil dari PID.

\section{Persentase Efisiensi Solar Tracker}

Solar tracker atau pelacak matahari merupakan piranti yang menjaga PV agar berada pada posisi optimum yang tegak lurus dengan radiasi matahari [6]. Berdasarkan tingkat kebebasan pergerakannya, solar tracker dibedakan menjadi dua tipe yaitu single axis (satu sumbu) dan dual axis (dua sumbu) solar tracker. Dari kedua tipe tersebut, terbagi lagi berdasarkan teknologi pelacakannya, yakni pasif, aktif, dan kronologis.

Secara matematis, presentasi efisiensi solar tracker ditulis sebagai berikut [7] :

$$
\text { \%Efisiensi }=\frac{\text { nilai optimasi 1-nillai optimasi } 2}{\text { nilai optimasi } 1} \times 100
$$

Nilai optimasi merupakan nilai yang didapatkan dari hasil pengujian panel surya.

\section{Motor DC}

Pada penelitian ini digunakan suatu penggerak berupa motor DC. Motor DC adalah alat yag mampu mengubah enegi listrik menjadi energi mekanik. Gambar sederhana dari motor DC adalah sebagai berikut.

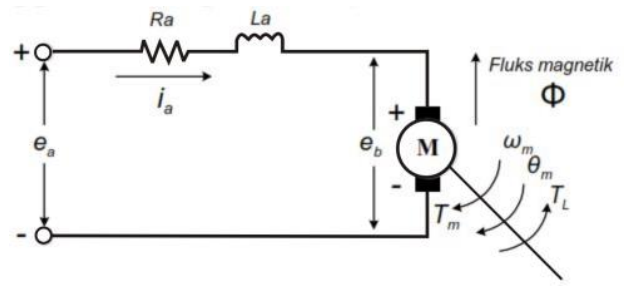

Gambar 1. Model Motor DC [8].

\section{E. Pengendali T2FSMC (Type 2 Fuzzy Sliding Mode Control)}

Pengendali T2FSMC merupakan pengendali yang dikembangkan dari penggabungan antara SMC dan FLC. Pengendali ini dirancang dengan menggunakan permukaan sliding. Skema untuk T2FSMC adalah sebagai berikut [9]:

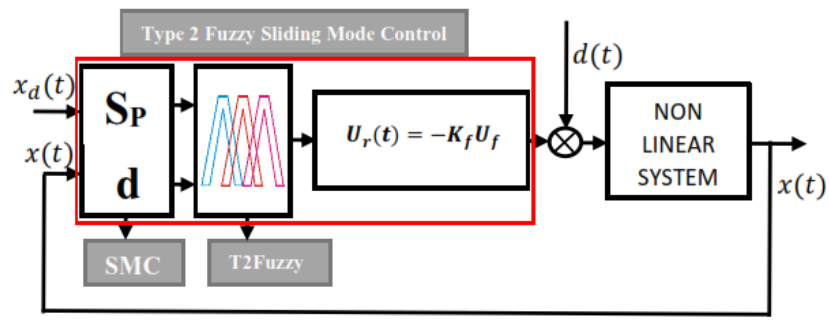

Gambar 2. Skema dasar pengendali T2FSMC [9].

\section{F. Kontrol PID(Proportional Integral Derivative)}

Sistem kontrol PID merupakan kontroler untuk menentukan persisi suatu sistem instrumen dengan karakteristik umpan balik (feedback) pada sistem tersebut. Sistem kendali ini terdiri dari tiga buah cara pengaturan yaitu kontrol P (Proportional), $\mathrm{D}$ (Derivate), dan I (Integral). Pengontrol ini akan memberikan aksi berdasarkan error yang diperoleh. Persamaan pengontrol PID adalah sebagai berikut [10] :

$$
u(t)=K_{p} e(t)+K_{\mathrm{i}} \int_{0}^{t} e(\tau) d \tau+K_{d} \frac{d e(t))}{d t}
$$

Dengan :

$$
\begin{gathered}
K_{\mathrm{i}}=K_{p} \times \frac{1}{T_{i}} \\
K_{d}=K_{p} \times T_{d}
\end{gathered}
$$

\section{Keterangan :}

$\mathrm{u}(\mathrm{t})$ = output pengontrol PID

$\mathrm{K}_{\mathrm{p}}=$ konstanta Proporsional

$\mathrm{T}_{\mathrm{i}}=$ konstanta Integral

$\mathrm{T}_{\mathrm{d}}=$ konstanta Derivative

$\mathrm{e}(\tau)=$ error (selisih antara set point dengan level aktual)

\section{ANALISA DAN PEMBAHASAN}

Pada bagian ini ditunjukkan perbandingan skema simulink pengendali T2FSMC dan PID dari penelitian sebelumnya. Selanjutnya dilakukan analisis data yang dihasilkan oleh prototype panel surya dengan melakukan perbandingan tegangan, arus, dan daya selama dua hari di waktu yang sama untuk kedua pengendali. Dari data tersebut dilakukan perhitungan persentasi efisiensi tegangan, arus, dan daya pengontrol T2FSMC terhadap PID. Kemudian dilakukan perhitungan energi yang dihasilkan saat diberi pengontrol T2FSMC dan PID pada data percobaan pertama dan kedua. Hasil perhitungan energi kedua pengendali tersebut dibandingkan dan kemudian akan diperoleh persentasi efisiensi energi pengontrol T2FSMC terhadap PID.

\section{A. Perbandingan Skema pengendali T2FSMC dan PID}

Perancanngan untuk kendali T2FSMC dan PID dilakukan dengan menggunakan software Simulank Matlab. Perancangan T2FSMC dilakukan dengan merancang sistem pengendali dengan metode SMC dan menentukan fungsi keanggotaan himpunan fuzzy dari SMC, membuat aturan fuzzy untuk menentukan control input dari rancangan SMC sebelumnya [11]. Desain dari pengendali T2FSMC ditunjukkan sebagai berikut. 


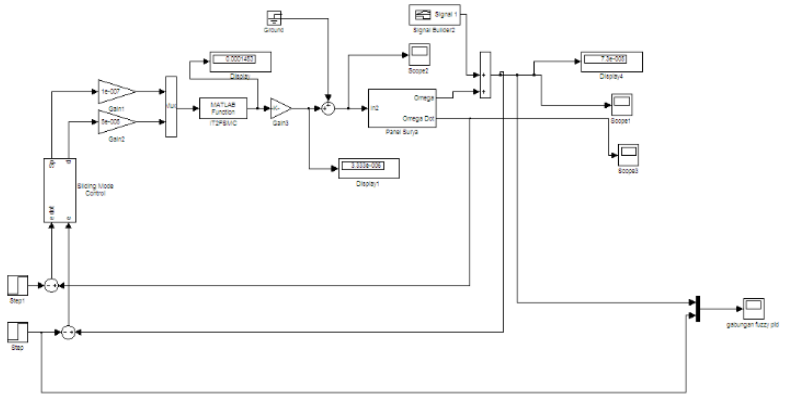

Gambar 3. Desain Kendali T2FSMC [11].

Perancangan PID dilakukan untuk kendali posisi sudut pada panel surya agar tetap stabil sesuai dengan nilai setpoint posisi sudut yang diberikan. Desain dari pengendali PID ditunjukkan sebagai berikut.

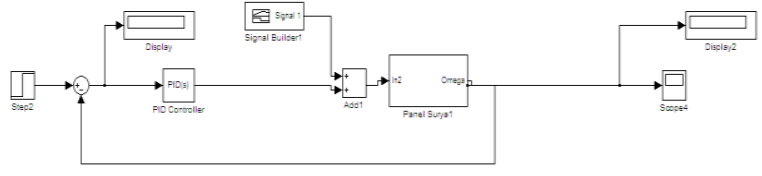

Gambar 4. Desain Kendali PID [11].

\section{B. Perbandingan Arus, Tegangan dan Daya Pengendali} T2FSMC dan PID

Pada sub bagian ini, dilakukan perbandingan arus, tegangan dan daya dari data yang dihasilkan oleh prototype panel surya yang telah diberikan pengendali T2FSMC dan PID. Pengambilan data dilakukan pada hari yang berbeda sehingga penambahan fluxmeter dijadikan data tambahan untuk dapat membandingkan kedua pengendali pada kondisi cahaya masuk yang sama.

Data yang dihasilkan dari prototype panel surya yaitu intensitas cahaya, arus dan tegangan. Nilai daya dari setiap pengendali diperoleh dengan mengalikan nilai arus dan tegangan dari data yang dihasilkan. Dari nilai intensitas cahaya yang diperoleh, diambil nilai intensitas cahaya yang paling tinggi yaitu sebesar 54612 Candela. Sehingga, perbandingan data yang dilakukan mengacu pada jumlah intensitas cahaya yang sama yaitu sebesar 54612 Candela dan waktu yang sama yaitu mulai pukul 09.00 sampai 14.30 dengan rentang waktu 5 menit per data yang dihasilkan. Jumlah data yang dibandingkan pada setiap percobaan yaitu sebanyak 67 data untuk masing-masing pengendali yang digunakan pada protoype panel surya.

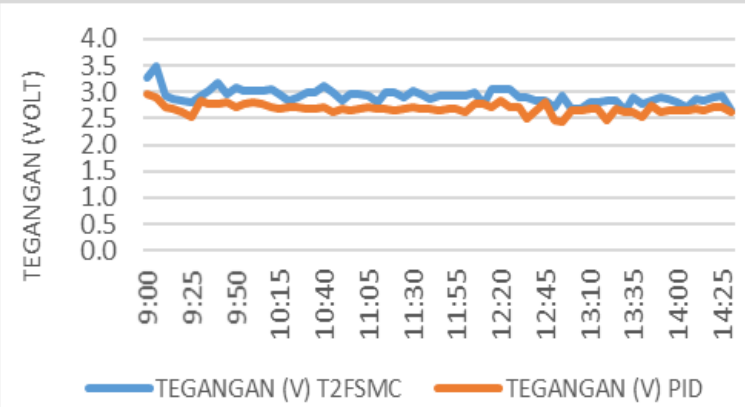

Gambar 5. Grafik perbandingan tegangan terhadap waktu antara pengendali T2FSMC dan PID pada percobaan pertama.

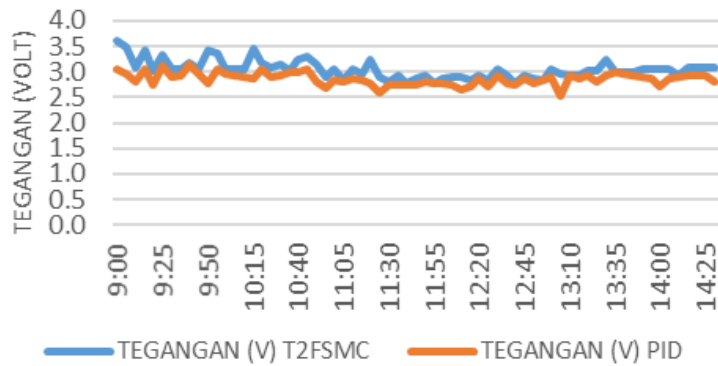

Gambar 6. Grafik perbandingan tegangan terhadap waktu antara pengendali T2FSMC dan PID pada percobaan kedua.

Dari kedua gambar diatas ditunjukkan bahwa pada percobaan pertama pengendali T2FSMC menghasilkan nilai tegangan terbesar pada pukul 09.05 yaitu sebesar 3,50 V dan terkecil pada pukul 14.30 yaitu sebesar 2,65 V, sedangkan pada percobaan kedua nilai tegangan terbesar terjadi pada pukul 09.00 yaitu sebesar 3,60 V dan terkecil pada pukul 12.40 yaitu sebesar 2,79 V.

Pada data pengendali PID dapat dilihat bahwa pada percobaan pertama nilai tegangan terbesar terjadi pada pukul 09.00 yaitu sebesar $2,97 \mathrm{~V}$ dan terkecil pada pukul 12.55 yaitu sebesar 2,43 V, sedangkan pada percobaan kedua nilai tegangan terbesar terjadi pada pukul 09.40 yaitu sebesar 3,15 V dan terkecil pada pukul 13.05 yaitu sebesar 2,53 V.

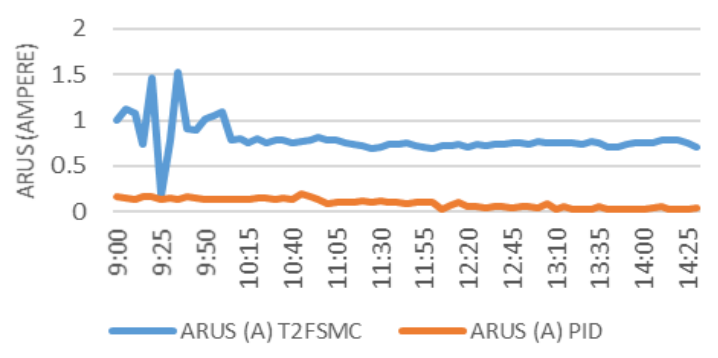

Gambar 7. Grafik perbandingan arus terhadap waktu antara pengendali T2FSMC dan PID pada percobaan pertama.

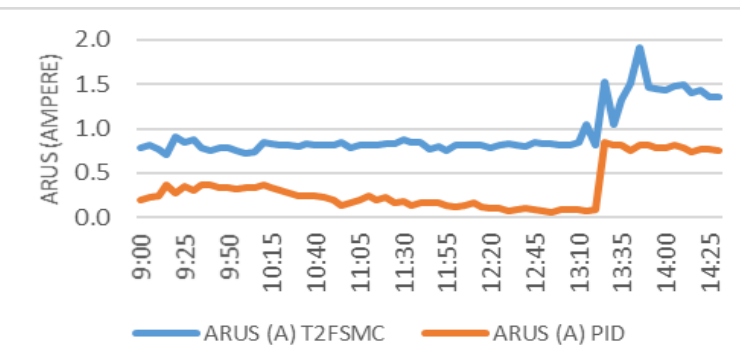

Gambar 8. Grafik perbandingan arus terhadap waktu antara pengendali T2FSMC dan PID pada percobaan kedua.

Nilai arus yang dihasilkan pada percobaan pertama untuk pengendali T2FSMC menghasilkan nilai terbesar yang terjadi pada pukul 09.35 yaitu sebesar 1,52 A dan terkecil pada pukul 09.25 yaitu sebesar $0,18 \mathrm{~A}$, sedangkan pada percobaan kedua nilai terbesar terjadi pada pukul 13.45 yaitu sebesar 1,91 A dan terkecil terjadi pada pukul 09.15 yaitu sebesar $0,70 \mathrm{~A}$.

Pengendali PID menghasilkan data pada percobaan pertama dengan nilai arus terbesar terjadi pada pukul 10.45 yaitu sebesar 0,19 A dan terkecil terjadi pada pukul 14.25 yaitu sebesar 0,03 A, sedangkan pada percobaan kedua nilai arus 
terbesar terjadi pada pukul 13.25 yaitu sebesar $0,84 \mathrm{~A}$ dan terkecil terjadi pada pukul 12.15 yaitu sebesar $0,06 \mathrm{~A}$.

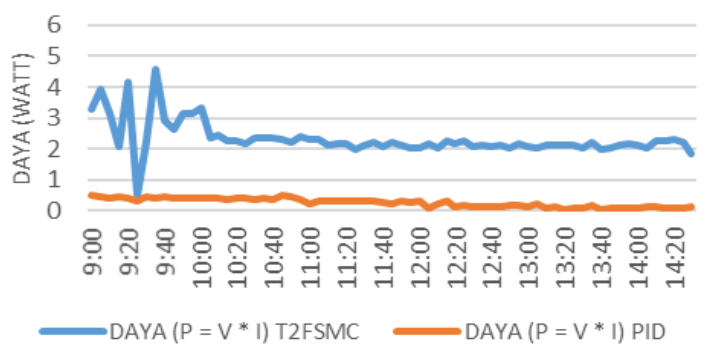

Gambar 9. Grafik perbandingan daya terhadap waktu antara pengendali T2FSMC dan PID pada percobaan pertama.

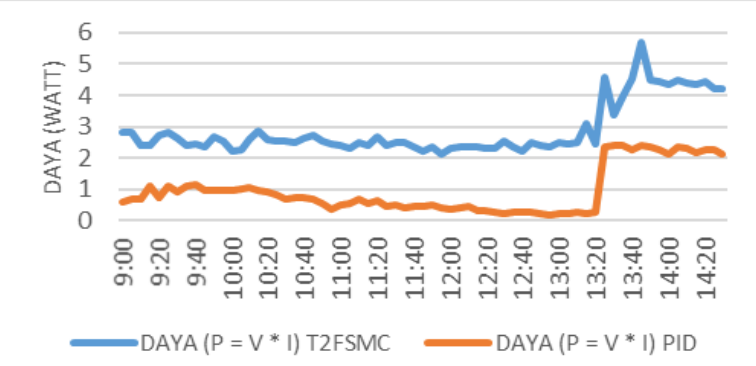

Gambar 10. Grafik perbandingan daya terhadap waktu antara pengendali T2FSMC dan PID pada percobaan kedua.

Pada percobaan pertama untuk perhitungan nilai daya pengendali T2FSMC diperoleh nilai daya terbesar terjadi pada pukul 09.35 dengan nilai $4,58 \mathrm{~W}$ dan terkecil terjadi pada pukul 09.25 dengan nilai $0,51 \mathrm{~W}$, sedangkan pada percobaan kedua diperoleh nilai daya terbesar terjadi pada pukul 13.45 dengan nilai $5,71 \mathrm{~W}$ dan terkecil terjadi pada pukul 11.55 dengan nilai $2,12 \mathrm{~W}$.

Untuk pengendali PID pada percobaan pertama diperoleh nilai daya terbesar terjadi pada pukul 10.45 yaitu sebesar 0,50 $\mathrm{W}$ dan terkecil terjadi pada pukul 13.20 yaitu sebesar $0,05 \mathrm{~W}$, sedangkan pada percobaan kedua diperoleh nilai daya terbsesar terjadi pada pukul 13.35 yakni sebesar 2,41 W dan terkecil terjadi pada pukul 12.55 yaitu sebesar $0,17 \mathrm{~W}$.

Data yang diperoleh saat menggunakan pengendali T2FSMC lebih tinggi dibandingkan dengan menggunakan pengendali PID baik itu pada data yang diperoleh pada percobaan pertama maupun percobaan kedua.

\section{Perhitungan Efisiensi Tegangan, Arus, dan Daya Pengendali T2FSMC terhadap Pengendali PID}

Perhitungan efisiensi dapat dilakukan dengan membandingkan selisih tegangan, arus, dan daya yang diperoleh dari pengendali T2FSMC dibandingkan dengan PID pada waktu yang sama dari data yang dihasilkan pada dua percobaan percobaan.

Dari grafik pada Gambar 11 - 12 di atas dapat dilihat bahwa perbandingan efisiensi tegangan terbesar pada percobaan pertama terjadi pada pukul 09.05 persentasi efisiensi $17,43 \%$, sedangkan yang terkecil terjadi pada pukul 12.10 dengan persentasi $0,36 \%$. Percobaan kedua, diperoleh perbandingan efisiensi terbesar terjadi pada pukul 09.50 sebesar $19,24 \%$ dan persentasi terkecil terjadi pada pukul 13.35 sebesar $0,33 \%$.

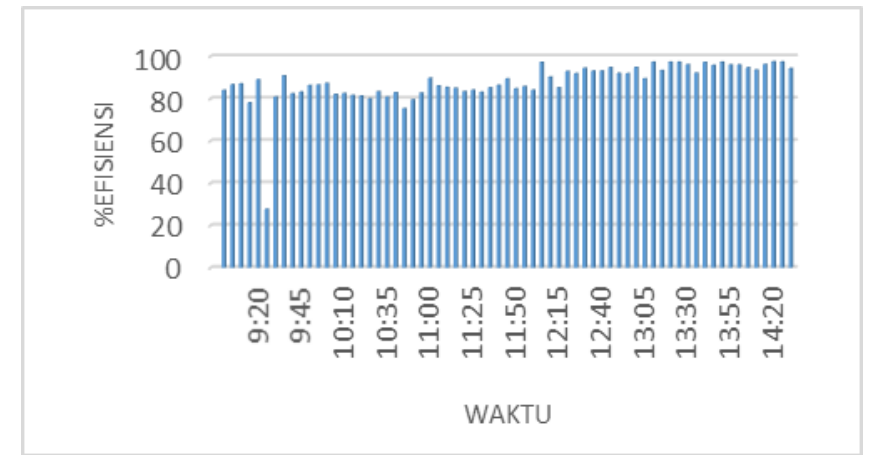

Gambar 11. Grafik perbandingan efisiensi tegangan pengendali T2FSMC dan PID pada percobaan pertama

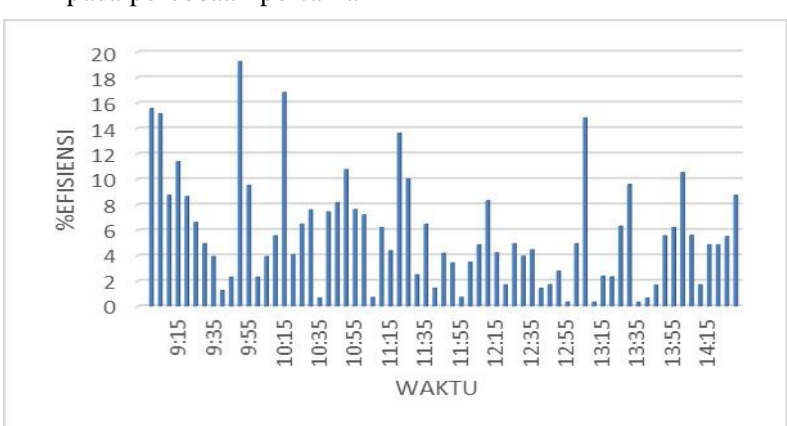

Gambar 12. Grafik perbandingan efisiensi tegangan pengendali T2FSMC dan PID pada percobaan kedua.

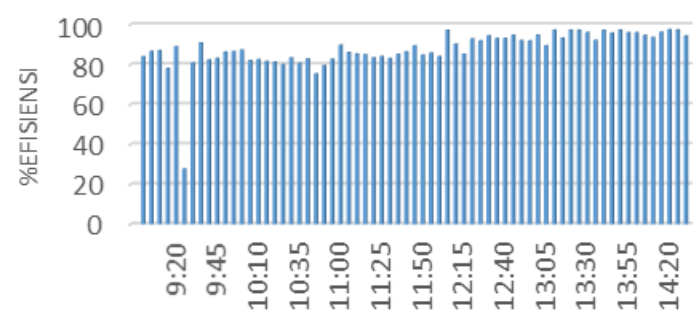

WAKTU

Gambar 13. Grafik perbandingan efisiensi arus pengendali T2FSMC dan PID pada percobaan pertama.

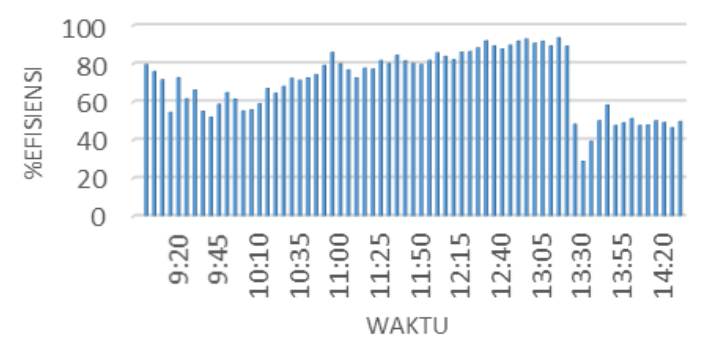

Gambar 14. Grafik perbandingan efisiensi arus pengendali T2FSMC dan PID pada percobaan kedua.

Persentasi efisiensi arus yang dihasilkan dari hasil perhitungan data pada percobaan pertama diperoleh bahwa nilai tertinggi yaitu pada pukul 14.20 sebesar $97,47 \%$ dan nilai terkecil pada pukul 09.25 sebesar $27,78 \%$. Sedangkan pada percobaan kedua nilai persentasi efisiensi arus paling tinggi terjadi pada pukul 13.15 yaitu sebesar $93,33 \%$ dan nilai terkecil terjadi pada pukul 13.30 sebesar $21,15 \%$. 


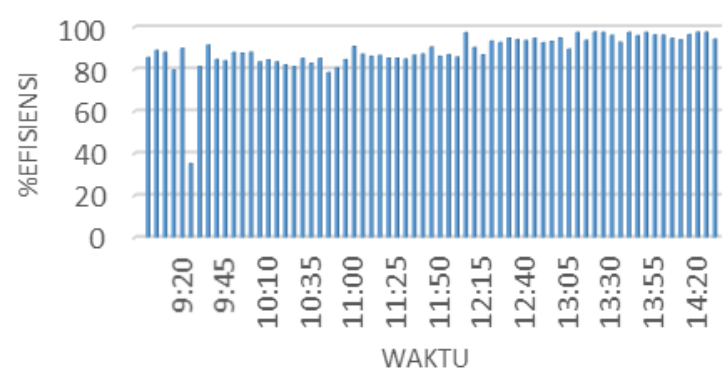

Gambar 15. Grafik perbandingan efisiensi daya pengendali T2FSMC dan PID pada percobaan pertama.

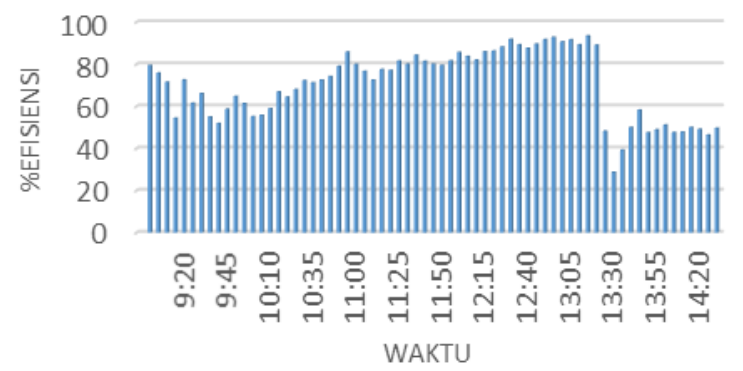

Gambar 16. Grafik perbandingan efisiensi daya pengendali T2FSMC dan PID pada percobaan kedua.

Pada percobaan pertama, persentasi efisiensi daya tertinggi terjadi pada pukul 13.20 yaitu sebesar $97,67 \%$ dan terkecil pada pukul 09.25 sebesar $35,20 \%$. Sedangkan pada percobaan kedua nilai tertinggi terjadi pada pukul 13.15 sebesar $93,49 \%$ dan terkecil pada pukul 13.30 yaitu sebesar $28,72 \%$.

Selanjutnya dilakukan perbandingan nilai rata-rata tegangan, arus, dan daya yang dihasilkan oleh prototype panel surya sebagai berikut.

Tabel 1.

Perbandingan nilai rata-rata tegangan, arus, dan daya

\begin{tabular}{lcccccc}
\hline \multirow{2}{*}{ KENDALI } & \multicolumn{2}{c}{ TEGANGAN } & \multicolumn{2}{c}{ ARUS } & \multicolumn{2}{c}{ DAYA } \\
\cline { 2 - 7 } & P 1 & P 2 & P 1 & P 2 & P 1 & P 2 \\
\hline T2FSMC & 2,92 & 3,05 & 0,79 & 0,95 & 2,33 & 2,88 \\
PID & 2,68 & 2,86 & 0,09 & 0,32 & 0,25 & 0,94 \\
\hline \hline
\end{tabular}

Dari perbandingan di atas diperoleh persentasi efisiensi pada percobaan pertama sebesar $8,22 \%, 88,61 \%$ dan $89,27 \%$ masing-masing untuk tegangan, arus dan daya. Sedangkan pada percobaan kedua, perbandingan persentasi efisiensi tegangan, arus dan daya dengan masing-masing nilai sebesar $6,23 \%, 66,32 \%$ dan $67,36 \%$. Secara keseluruhan dapat dilihat bahwa dengan pengendali T2FSMC diperoleh efisiensi yang lebih tinggi. Dari persentasi efisiensi di atas dapat dilihat bahwa untuk tegangan, arus dan daya memiliki nilai efisiensi paling tinggi pada percobaan yang pertama.

\section{Perbandingan Nilai Energi Pengendali T2FSMC dan PID}

Perhitungan nilai energi dari pengendali T2FSMC dan PID dilakukan untuk mengetahui efek tracking dari performa sistem panel surya.
Tabel 2.

Perbandingan Nilai Energi Pengontrol T2FSMC dan PID JUMLAH ENERGI (Wh)

\begin{tabular}{ccc}
\cline { 2 - 3 } PENGONTROL & $\begin{array}{c}\text { PERCOBAAN } \\
\text { PERT AMA }\end{array}$ & $\begin{array}{c}\text { PERCOBAAN } \\
\text { KEDUA }\end{array}$ \\
\hline T2FSMC & $12, .99$ & 16,07 \\
PID & 1,39 & 5,24 \\
\hline \hline
\end{tabular}

Dari Tabel 3.2 dapat dilihat bahwa nilai energi yang dihasilkan oleh pengendali T2FSMC lebih besar dibandingkan PID yaitu dengan selisih sebesar $11,60 \mathrm{Wh}$ pada percobaan pertama dan 10,83 Wh pada percobaan kedua.

Selanjutnya dari perbandingan nilai energi tersebut dapat diperoleh persentasi efisiensi energi pengendali T2FSMC terhadap PID. Kenaikan nilai efisiensi energi yang dihasilkan oleh optimasi menggunakan pengendali T2FSMC dibandingkan dengan pengendali PID sebesar $89,30 \%$ atau setara dengan energi yang dihasilkan setiap 5 menitnya lebih tinggi sebanyak 11,60 Wh dibandingkan dengan menggunakan pengendali PID. Sedangkan pada percobaan kedua, kenaikan nilai efisiensi energi pengendali T2FSMC sebesar 67,39\% atau setara dengan energi yang dihasilkan setiap 5 menitnya lebih tinggi sebesar 10,83 Wh dibandingkan dengan menggunakan pengendali PID.

\section{KESIMPULAN}

Berdasarkan hasil analisis dan pembahasan pada bagian sebelumnya, dapat diambil kesimpulan sebagai berikut.

1. Pengendali T2FSMC menghasilkan data tegangan, arus, dan daya paling tinggi dibandingkan dengan pengendali PID.

2. Dari dua percobaan perbandingan data yang dilakukan dapat dilihat bahwa hasil paling bagus terjadi pada data yang diperoleh pada percobaan pertama yaitu saat menggunakan pengendali T2FSMC.

3. Pada percobaan pertama perbandingan efisiensi data pengendali T2FSMC dan PID diperoleh efisiensi rata-rata tegangan sebesar $8,22 \%$, efisiensi rata-rata arus sebesar $88,61 \%$ dan efisiensi rata-rata daya sebesar $89,27 \%$. Sementara untuk percobaan kedua, perbandingan efisiensi data pengendali T2FSMC dan PID diperoleh efisiensi ratarata tegangan sebesar $6,23 \%$, efisiensi rata-rata arus sebesar $66,32 \%$ dan efisiensi rata-rata daya sebesar $67,36 \%$.

Perbandingan efisiensi energi keluaran pengendali T2FSMC dan PID pada percobaan pertama adalah sebesar 89,30\% dengan selisihnya mencapai 11,60 Wh. Sedangkan pada percobaan kedua, Perbandingan efisiensi energi keluaran pengendali T2FSMC dan PID adalah sebesar 67,39\% dengan selisihnya mencapai $10,83 \mathrm{Wh}$.

\section{DAFTAR PUSTAKA}

R. Asti, "Optimasi Posisi Panel PV Menggunakan Dual Axis Solar Tracker Berbasis Metode Perturb and Observe pada 
Sistem PV Tower Mikrogrid Skala Laboratorium," Surabaya, 2016.

[2] N. R. Mardlijah and A. Rahmita, "Type 2 Fuzzy Sliding Mode Control (T2FSMC) Controller on Solar Panel Prototype Using The Most Representative Parameters," J. Theor. Appl. Inf. Technol., vol. 95, no. 20, 2017.

[3] P. B. S., "Identifikasi Parameter Model Matematika pada Penggerak Prototype Panel Surya," Surabaya, 2017.

[4] R. Hafiyyan, "Perbandingan Pengendali T2FSMC dan Pengendali PID pada Prototype Panel Surya," Surabaya, 2017.

[5] S. Ozcelik, "Two-Axis Solar Tracker Analysis and Control for Maximum Power Generation," in Procedia Computer Science, 2011, pp. 457-462.

[6] H. Mousazadeh, "A Review of Principle and Sun-Tracking Methods for Maximizing Solar System Output," Renew. Energy Sustain. Energy Rev., vol. 13, pp. 1800-1818, 2013.
S. Roni, "Rancang Bangun Solar Tracker Berbasis Mikrokontroler Atmega8535 dengan Sensor LDR dan Penampil LCD," J. Fis. UNAND, vol. 4, no. 2, 2015.

[8] W. I. Mardlijah and I. G. N. R. Usadha, "Desain Kontrol Posisi pada Panel Surya dengan Menggunakan Metode Fuzzy Sliding MOde Control (FSMC)," Limits, vol. 6, no. 1, pp. 35-50, 2009.

[9] Mardlijah, Subiono, Sentot, and Y. Efprianto, "On designing of the driven susytem control of solar panels using type 2 fuzzy sliding mode control (T2FSMC)," in AIP Conference Proceedings, 2016.

[10] D. A. Rochman, "Modul Kontrol Temperatur Air Berbasis PID Menggunakan Matlab Simulink," Semarang, 2013.

[11] F. Anggita, "Perbandingan Kontrol PID dan T2FSMC pada Prototype Panel Surya dengan Mempertimbangkan Intensitas Cahaya," Surabaya, 2017. 